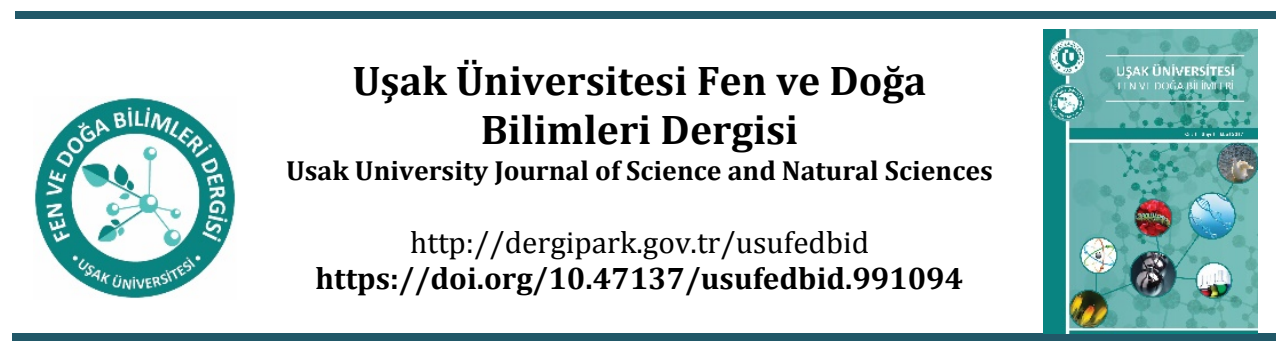

Araştırma makalesi

\title{
Dışmerkez Çelik Çaprazların Yapılar Üzerindeki Etkilerinin İncelenmesi
}

\author{
Soner Şeker*, Ömer Tunç, Dima Börekçi, Batuhan Göktaş \\ İnşaat Mühendisliği Bölümü, Mühendislik Fakültesi, Uşak Üniversitesi, Uşak, Türkiye \\ Geliş: 5 Eylül 2021 \\ Kabul: 22 Kasım 2021 / Received: 5 September 2021 \\ Accepted: 22 November 2021
}

\begin{abstract}
Steel braces are used in steel frames system, in order to resist lateral loads such as seismic and wind. In this study, the contributions of eccentr ic steel braces on low-rise structures, among the brace types defined in the regulations, are discussed in against the lateral loads in steel structures. For this purpose, the 3- and 5-storey structures, which were designed as a non-braced frame system, were redesigned using eccentric braces defined in the literature. The appearance of the sample buildings in the plan is identical and there are 8 spans in the $\mathrm{X}$ direction and 4 spans in the Y direction in the modeled structures. Models; non-braced steel frame, eccentric diagonal brace, eccentric $\mathrm{V}$ brace and eccentric inverted $\mathrm{V}$ brace were added and analyzed. Considered sample structures; The total weight of the structure, the maximum lateral displacement value and the period values of the structures were compared. In the analysis and design of buildings; Turkey Building Earthquake Regulation (TBDY 2018), Principles for the Design, Calculation and Construction of Steel Structures (ÇYTHYE), TS-498, TS EN 1991-1-3 and TS EN 1991-1-4 standards were used. Structural analyzes were made with the SAP2000 program. As a result of the analysis, it was observed that the eccentric braces used had a positive effect on the lateral displacement of the structure.
\end{abstract}

Keywords: Steel structures, moment resisting frame, steel braces, eccentric steel braces.

\section{Özet}

Çelik çerçeve sistemlerde, deprem ve rüzgâr gibi yanal yüklerin karşılanması amacıyla çelik çapraz elemanlar kullanılmaktadır. Bu çalışmada, çelik yapılarda yanal yükleri karşılamak amacıyla yönetmeliklerde tanımlanmış olan çapraz türleri içerisinden, dış merkezi çelik çaprazların az katlı yapılar üzerindeki katkıları ele alınmaktadır. Bu maksatla çaprazsız bir şekilde oluşturulan çerçeve sistem olarak tasarımı yapılmış olan 3 ve 5 katlı yapılar, literatürde tanımlanan dışmerkez çaprazlar kullanılarak yeniden tasarlanmıştır. Örnek yapıların plandaki görüntüsü özdeş olup modellenen yapılarda X doğrultusunda 8 açıklık, Y doğrultusunda ise 4 açıklık bulunmaktadır. Yapı modellerinin; çaprazsız moment aktaran çelik çerçeve, dıșmerkez diyagonal çapraz, dışmerkez V çapraz ve dișmerkez Ters V çaprazlar eklenerek Mod Birleştirme Yöntemi ile analizi yapılmıştır. Ele alınan örnek yapılar için; toplam yapı ağırlığı, en büyük yanal yer değiştirme değeri ve yapıların periyot değerleri karşılaştırılmıştır. Yapıların analiz ve tasarımında; Türkiye Bina Deprem Yönetmeliği(TBDY 2018), Çelik Yapıların Tasarım, Hesap ve Yapımına Dair Esaslar(ÇYTHYE) , TS-498, TS EN 1991-1-3 ve TS EN 1991-1-4 standartlarından

*Corresponding author:

E-mail: soner.seker@usak.edu.tr (ORCID ID: 0000-0002-7632-9713) 
yararlanılmıştır. Yapısal analizleri ise SAP2000 programı ile yapılmıştır. Analiz sonucunda kullanılan dışmerkez çaprazların yapıya yanal yönde yer değiștirmede olumlu etki ettiği gözlemlenmiştir.

Anahtar Kelimeler: Çelik Yapılar, moment aktaran çerçeve, çelik çaprazlar, dı̧s merkez çelik çaprazlar.

(C)2021 Usak University all rights reserved.

\section{Giriş}

Mühendislik ürünü olan her yapının, işlevini sürdürebilmesi için, yapılarda etkili olan tüm yükler altında belirli bir dayanım ve rijitliği sağlaması gerekmektedir. Yapıların tasarımında, ilgili yönetmeliklerin öngörmüş olduğu yükler dikkate alınarak en uygun tasarım ortaya çıkarılmaktadır. Yapılarda her an etkili olan düşey yükler; ölü ve hareketli yüklerden oluşurken, farklı zaman aralığı içinde yatay yönde etki eden yükler ise rüzgâr ve deprem yükleridir. Dinamik yükler olarak da anılan bu yatay yükler, taşıyıcı sistem tasarımında kritik kesiti belirleyici unsur olarak rol alırlar. Zamanı ve şiddeti önceden bilinemediği için yapı dinamiğinin temel unsurunu deprem yükü oluşturur.

Yapılan çalıșmalarda; yapıların deprem etkisi altındaki davranışlarını irdeleyen birçok bilimsel çalışmalara rastlanılmaktadır. Daha önce yaşanan afetler ve depremlerden edinilen tecrübeler sayesinde depreme dayanıklı yapı tasarımında yapılan doğru ve yanlışlıklar gözler önüne serilmiştir.

Son yıllarda çelik yapıların kullanım alanları gün geçtikçe artmaktadır. Çelik yapılar daha çok; endüstriyel yapılar, yüksek katlı yapılar, spor tesisleri vb. yapılarda tercih edilmektedir. Çelik yapıların da deprem anındaki performansını iyileştirecek birçok yöntem geliştirilerek denenmiştir. Bunlardan birisi de çalışma konumuz olan çelik çapraz perdelerdir.

$\mathrm{Bu}$ çalışmada, aynı kat planlarına sahip az katlı yapılar, herhangi bir çapraz kullanılmadan moment aktaran çerçeve sistemler olarak tasarımı yapılmıştır. Çapraz kullanılmadan tasarımı yapılmış olan örnek yapılara literatürde bahsi geçen dışmerkez çelik çaprazlar uygulanarak, yapıların periyot, yanal yerdeğiştime ve yapısal ağırlık değerlerindeki değişimler gözlemlenmiştir. Özellikle, yapılarda önemli bir tasarım sınırlayıcısı olan yanal ötelenmenin yüksek yapılarda az katlı yapılarda daha fazla olması bilinmektedir. Çalışmada ise çelik çaprazların etkilerinin, yapı yüksekliklerine bağlı olarak değişimini gözlemlemek adına seçilen örnek yapılar 3 katlı ve 5 katlı modeller olarak belirlenmiștir.

Çelik çaprazların, sadece çelik yapılarda değil mevcut betonarme yapıların yatay rijitliğini artırmaya yönelik katkısının olduğu da yapılan çalışmalarda görülmektedir. Yapılan çalışmalarda, çelik çaprazlar ile yerinde dökme betonarme deprem perdelerinin performans karşılaştırılmaları da incelenmiştir [1,12]. Yönetmeliklerde bahsi geçen süneklik düzeyi yüksek merkezi çelik çaprazlı perdelerin tasarım kuralları hakkında incelemeler yapılmıştır $[2,14,16]$. Bazı çalışmalarda; çelik çapraz tiplerinin betonarme deprem perdelerine göre karşılaştırılması yapılmasıyla birlikte çelik çapraz tiplerinin kendi içinde kıyaslanması ve çaprazların moment aktaran çerçevelerin yatay rijitliklerine olan katkıları da ele alınmıştır [3-6,9,10,17]. Ayrıca yönetmeliklerde tanımlanmış olan merkezi çaprazlı çelik çerçevelerin deprem performansları doğrusal olmayan analiz yöntemiyle sismik performansları ele alınmıştır [7]. Bazı çalışmalarda ise yapılarda kullanılan çapraz türleri farklı yönetmelik kriterleri için değerlendirilerek, karşılaştırılmıştır [8,13]. Ayrıca, çapraz tipinin önemi kadar çaprazlarda kullanılan en kesit türüne yönelik de çalışmalar olduğu görülmektedir $[11,20]$. 
Çelik çapraz elemanlarının yapı davranışına olan katkısı ve çalışma prensiplerinin bilinmesi yapı davranıșını tahmin etme açısından bir yol göstericidir. Caprazların kullanıldığı çelik çerçeve sistemler, deprem etkilerine karșı sağladıkları rijitlik nedeniyle son dönemde yaygın bir şekilde kullanılmaktadır [15]. Çerçeve sistemlerde gelen yatay ve düșey yükler kolon ve kiriș yani çerçeve sistem ile tașınmakta iken çaprazların kullanıldığı çerçevelerde ise çapraz elemanlarda yük paylașımında aktif rol oynamaktadır[18,19]. Capraz elemanların kullanılma sebebi yapıya yatay stabilite kazandırmak olması sebebiyle bu elemanlar yatay yük aktarımı yapabilecek şekilde tasarımı yapılmalıdır.

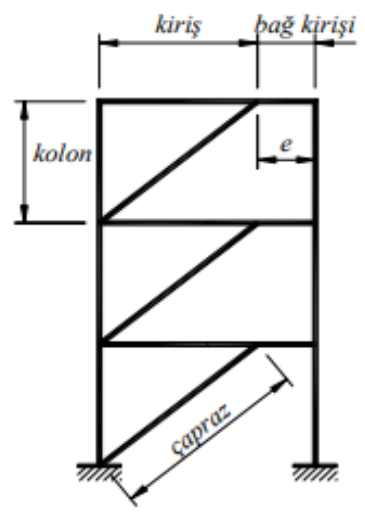

(Dışmerkez Diyagonal )

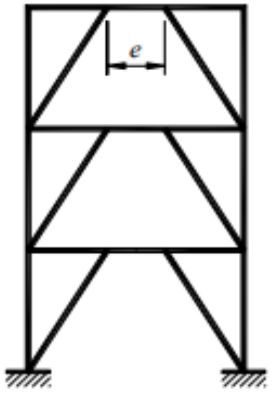

( Dışmerkez Ters V)

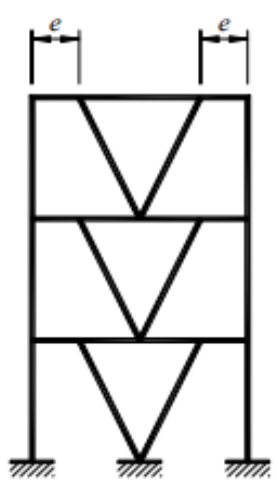

( Dişmerkez V)

Şekil 1. Dış Merkez Çelik Çapraz Tipleri

Araştırma kapsamında 3 ve 5 katlı çelik bir yapı moment aktaran çerçeve olarak ve aynı yapı Dışmerkez Diyagonal çapraz, Dışmerkez V çapraz ve Dışmerkez Ters V çaprazlar eklenerek bu çapraz tiplerinin yapılarda ortaya koydukları etkilerin irdelenmesi amaçlanmıştır.

Çelik yapılar kolon, kiriș ve çapraz çelik elemanlardan oluşan çerçeve sistemlerdir. Çelik çaprazlar yapıyı yatay etkilere karşı rijitliğini artırarak yanal yer değiștirmelerin azalmasına yardımcı olmaktadır. Dışmerkez çelik çerçevelerin en az bir ucu kirişte bağ kirişi adı verilen bir kısma bağlanır. Şekil 1'de Dışmerkez çapraz türleri yer almaktadır.

\section{Materyal ve Yöntem}

Çalışmada; yapılara etkiyen deprem yüklerin belirlenmesinde TBDY 2018 yönetmeliğinden faydalanılarak, taşıyıcı sistem elemanlarının boyutlandırılması ÇYTHYE2016 kriterleri dikkate alınarak belirlenmiștir. [21,24]. Rüzgâr yükü, kar yükü ve döșeme hareketli yükleri ise TS EN 1991 -1- 4, TS EN 1991 -1- 3 ve TS 498 `e göre belirlenmiștir $[20,22]$.

Yapı modellerinin oluşturulması ve analiz aşamasında SAP2000 v19.2.1 yapısal analiz programı kullanılmıştır [25].

Çalışmada ele alınan örnek yapılar 3 ve 5 katlı olarak; X yönünde 8 açıklıklı, Y yönünde 4 açıklıklı olarak simetrik bir şekilde tasarlanmıştır (Şekil 2). Yapıların giriş katlarında; kat 


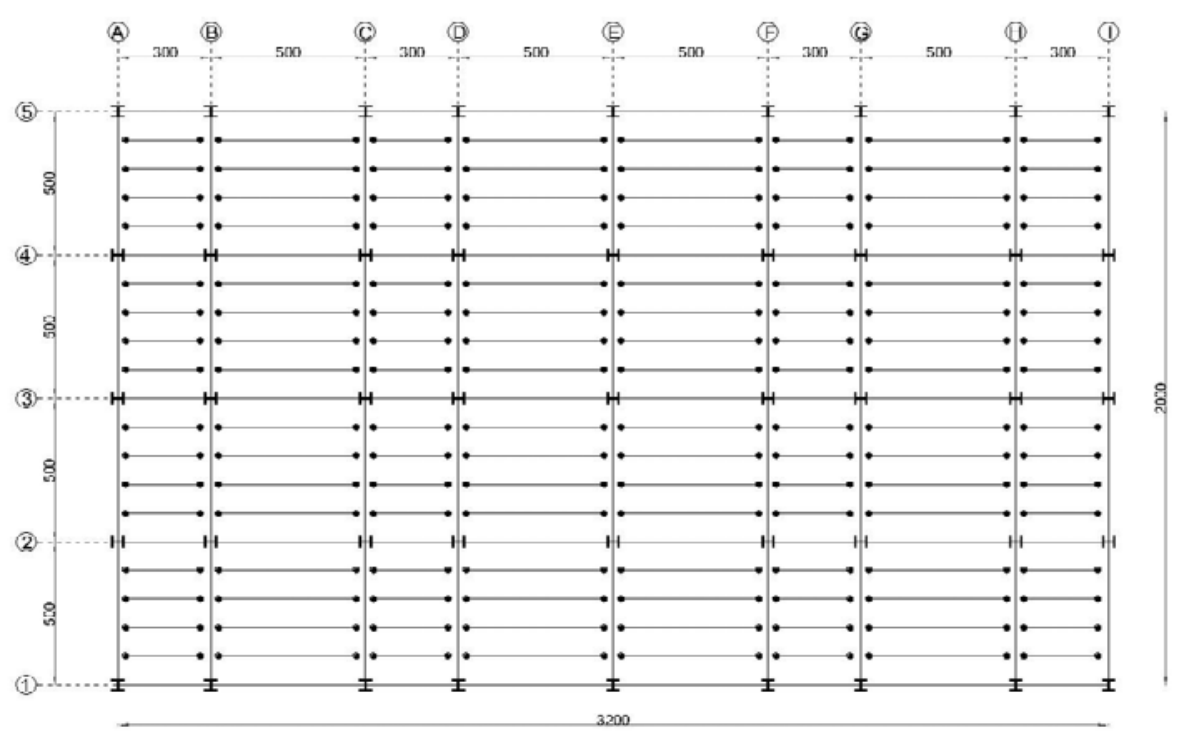

yükseklikleri ticari kaygllar düşünülerek 4 metre diğer katlarda ise 3.25 metre olarak tercih edilmiștir.

Şekil 2. Yapılara ait tipik kat planı

Şekil 2'de çalışmada ele alınan yapılara ait tipik kat planı yer almaktadır. İncelenen 3 ve 5 katlı yapıların her biri için herhangi bir çapraz kullanılmayan çerçeve sistem ve 3 adet farklı diş merkezi çelik çerçeve sistem olarak çözülmüştür. Yapılar; moment aktaran çerçeve sistem, Dışmerkez V çapraz, Dışmerkez Ters V, Dışmerkezi Diyagonal çapraz olarak adlandırılmıştır.

İncelenen yapılar Uşak ilinde yer aldığı düşünülerek, yapı koordinatlarının enlemi ve boylamı sırasıyla $38.687476^{\circ}, 29.45946^{\circ}$ şeklindedir. Zemin sınıfı ZD olup Türkiye Deprem Tehlike Haritaları interaktif Web Uygulamasından alınan veriler aşağıdaki gibidir.

$S_{s}=0.673 S_{1}=0.165 S_{D S}=0.849 S_{D 1}=0.375 T_{A}=0.088(s) T_{B}=0.441(s) T_{L}=$ $6.000(s)$. Bina önem katsayısı I=1.0 alınmıştır. Mod birleştirme analiz için kullanılan yatay elastik tasarım spektrumu Şekil 3'te görülmektedir.

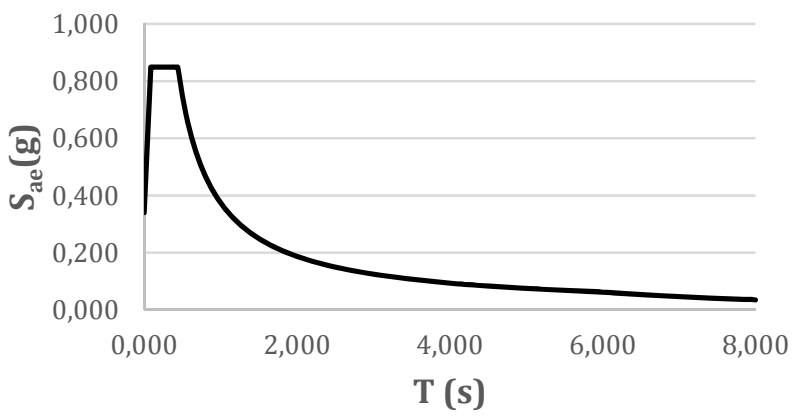

Şekil 3. Yatay Elastik Tasarım Spektrumu 
İlgili yönetmeliklerden yapılarda etkili olması öngörülen yük etkileri Sap2000 programındaki hazırlanmıș olan modellere tanımlanmıștır. Binanın zati ağırlığı programın bünyesinde mevcuttur. Sistemdeki kar yükü TS-EN-1991-1-3'e göre $75 \mathrm{~kg} / \mathrm{m}^{2}$ olarak belirlenmiștir. Yük parametrelerinden birisi olan rüzgâr yükleri ise TS-EN-1991-14'te yer alan koşullara bağlı kalarak Sap2000 programına otomatik olarak yüklenmiștir.

\section{Bulgular}

\subsection{Katlı Çelik Taşıyıcı Sistemde Çelik Çaprazların Etkisinin İncelenmesi}

Çelik çaprazların yapılarda, yapısal davranış değerlerine olan etkisinin araștırılması ve en uygun çapraz türünün belirlenmesi amacıyla öncelikle 3 katlı bir yapı modeli incelenmiștir. Yapılan analizler neticesinde herhangi bir çelik çapraz türü kullanılmaksızın boyutlandırılan yapı ağırlı̆̆ 13474 kN olarak ele edilmiştir.
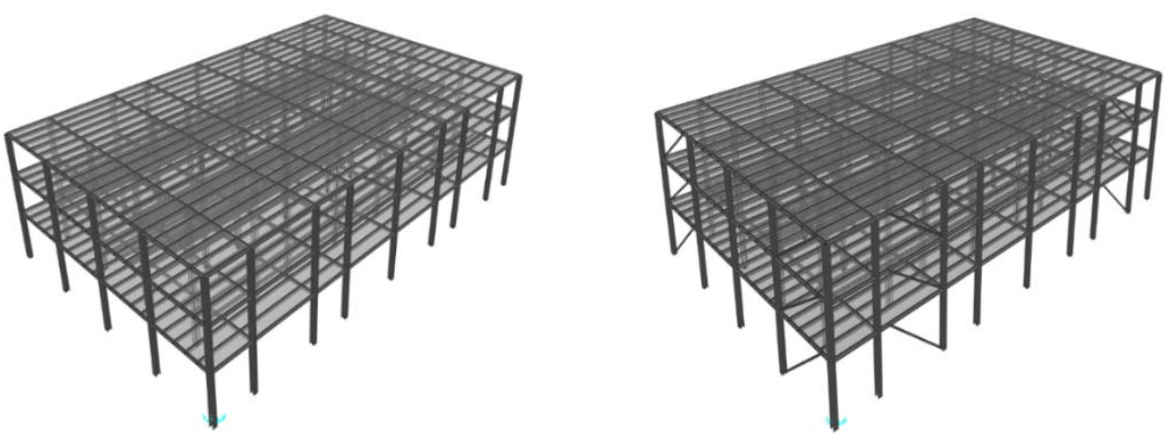

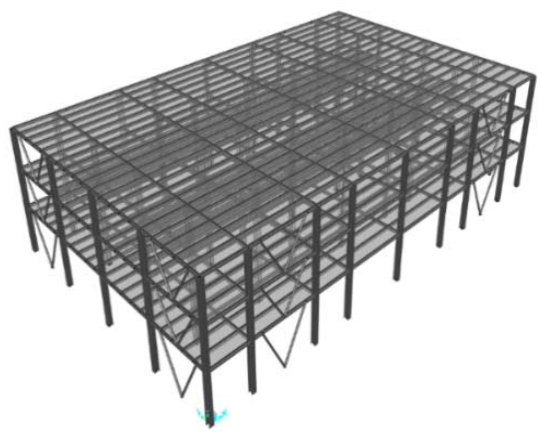

Moment Aktaran Çerçeve Model

Dışmerkez V Çaprazlı Model

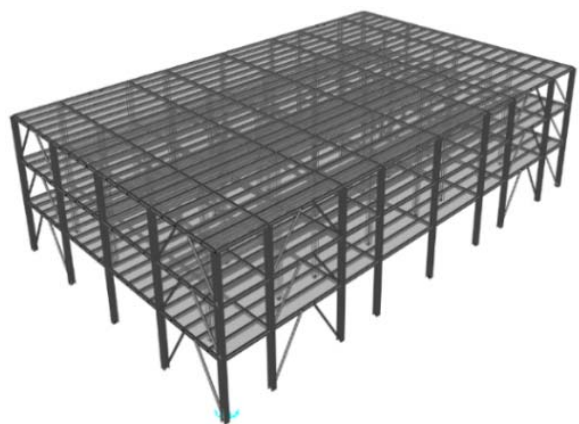

Dışmerkez Diyagonal Çaprazlı Model

Dışmerkez Ters V Çaprazlı Model

Şekil 4. 3 Katlı yapı örnekleri

Moment aktaran 3 katlı yapıya dıșmerkez çaprazlar uygulanarak analiz edilmiștir (Şekil 4). Analizler sonucunda ele alınan örnek yapıya ait elde edilen değerler Tablo 1'de görülmektedir. 
Tablo 1 . 3 Katlı Yapıya Ait Analiz Sonuçları

\begin{tabular}{lcccc}
\hline \multicolumn{1}{c}{ 3 Katlı Yapı } & Ăğırlık (kN) & $\begin{array}{c}\text { Periyot } \\
\text { Mod1 (sn) }\end{array}$ & \multicolumn{2}{c}{ Tepe Noktası Yerdeğiştirmesi } \\
& & X Yönü (mm) & Y Yönü (mm) \\
\hline Moment Aktaran & 13474 & 0.89 & 12.32 & 14.96 \\
Dışmerkez Diyagonal & 13484 & 0.77 & 10.59 & 11.41 \\
Dışmerkez V & 13494 & 0.62 & 9.47 & 10.38 \\
Dışmerkez Ters V & 13494 & 0.61 & 8.95 & 9.56 \\
\hline
\end{tabular}

Tablo 1'de 3 katlı yapıya ait 4 farklı model için elde edilmiş olan; toplam yapı ağırlığı, periyot ve her iki doğrultudaki tepe noktası deplasmanları yer almaktadır. Tasarımı yapılan moment aktaran çerçeve sistemlerde çerçeve sistemi oluşturan elemanların boyutları değiştirilmeksizin yapılara dışmerkez çaprazlar uygulanarak, bu çaprazların etkisi gözlemlenmiştir. Moment aktaran modele göre yapı ağırlıklarında gözlenen değişim uygulanan çaprazların ağırlıklarından kaynaklanmaktadır. Bu sebeple; Dışmerkez V ve Dışmerkez Ters V çaprazların eleman sayılarında ki fazlalıktan dolayı Dışmerkez Diyagonal Çapraza göre daha ağır olduğu görülmektedir.

Çelik çaprazların, yapılara yatay rijitlik konusunda yapmış oldukları katkılar yapılara ait periyot değerlerinin çapraz kullanılan modellerde daha düşük olmasından anlaşılmaktadır. Her bir modelin analizi sonucunda elde edilen değerler kıyaslandığında; en büyük katkıyı Dışmerkez Ters V çaprazların kullanıldığı yapılarda gözlemlendiği rahatlıkla söylenebilir. Yine tablodaki değerlerden anlaşıldığı üzere Dışmerkez Ters V çaprazların kullanıldığı yapıların salınımı en fazla sınırlandırıldığı görülmektedir.

Ele alınan örnek yapıda moment aktaran çerçeveli yapıya sadece çapraz elemanlar eklenerek yanal rijitliklerinin arttığı görülmüştür. Yatay yerdeğiştirme değerlerinin önemli bir tasarım sınırlayıcısı olduğu düşünülerek, örnek modellerin çapraz elemanlarla birlikte tekrar analiz edilerek en ekonomik tasarımı yapılmış ve elde edilen değerler Tablo 2'de görülmektedir.

Tablo 2. 3 Katlı Yapılarda Çapraz Elemanların Etkileri

\begin{tabular}{lcccc}
\hline \multicolumn{1}{c}{ Yapının Tekrar } & Ağırlık & Periyot & \multicolumn{2}{c}{ Tepe Noktası Yerdeğiştirmesi } \\
Boyutlandırılmış Hali & (kN) & Mod1 (sn) & X Yönü (mm) & Y Yönü (mm) \\
\hline Moment Aktaran & 13474 & 0.89 & 12.32 & 14.96 \\
Dışmerkez Diyagonal & 13111 & 0.81 & 11.68 & 12.23 \\
Dışmerkez V & 13268 & 0.74 & 7.68 & 10.74 \\
Dışmerkez Ters V & 13258 & 0.65 & 7.15 & 10.69 \\
\hline
\end{tabular}

Tablo 2' de görüldüğü üzere bu yapı için Dışmerkezi Ters V modellenip tekrar boyutlandırılmış modelin yapı ağırlığı azalırken yanal rijitlik bakımından en uygun tercih olabileceği gözükmektedir. Ele alınan örnek yapıda kullanılan Dışmerkez Ters V çaprazlar, moment aktaran çerçeveden farklı olarak yapının ağırlığında sınırlı bir azalmayı sağlamış olsa da yatay yönde yer değiştirme konusunda ciddi bir katkısının olduğu görülmektedir. Dışmerkez Ters $\mathrm{V}$ çaprazlar kullanıldığında tepe noktası 
yerdeğiştirmesi değerleri X yönünde yaklaşık \%42, Y yönünde ise yaklaşı \%29 kadar azaldığı anlaşılmaktadır.

\subsection{Katlı Çelik Taşıyıcı Sistemde Çelik Çaprazların Etkisinin İncelenmesi}

Çelik çaprazların yüksek yapılarda, yapısal
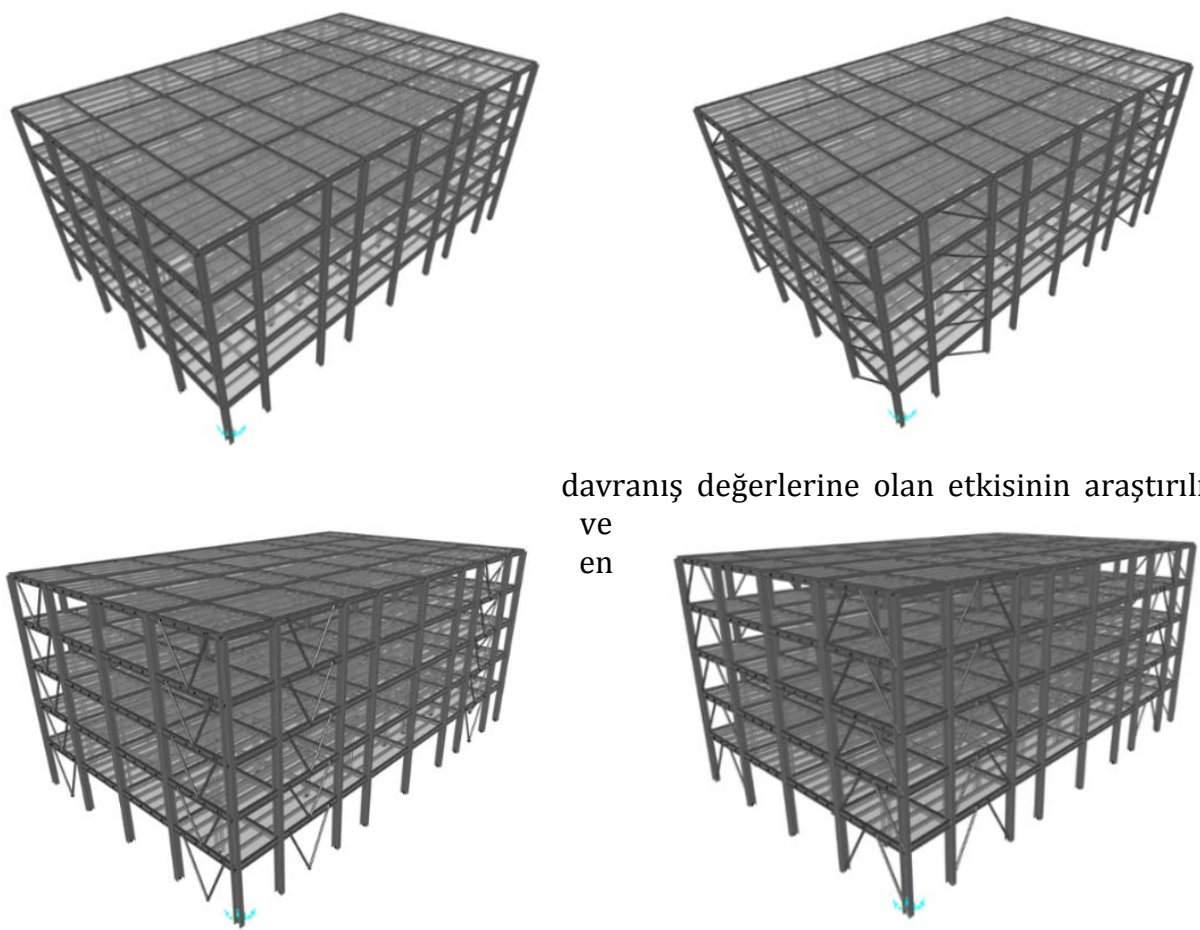

davranış değerlerine olan etkisinin araştırılması ve

en

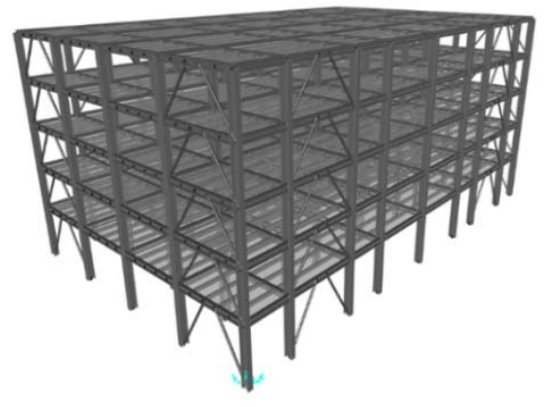

uygun çapraz türünün belirlenmesi amacıyla ele alınan örnek yapı olarak 5 katlı modeller ele alınmıștır (Șekil 5). Moment aktaran 5 katlı yapıya dıșmerkez çaprazlar uygulanarak analiz edilmiştir. Analizler sonucunda ele alınan örnek yapıya ait elde edilen değerler Tablo 3'te görülmektedir.

Moment Aktaran Çerçeve

Dışmerkez V Çaprazlı Model
Dıșmerkez Diyagonal Çaprazlı Model

Dışmerkez Ters V Çaprazlı Model 
Şekil 5. 5 Katlı yapı örnekleri

Tablo 3'de 5 katlı örnek olarak ele alınan 4 farklı modele ait; toplam yapı ağırlıkları, periyot değerleri ve yapının tepe noktasındaki $X$ ve $Y$ yönünde yapmış olduğu maksimum yer değiştirme değerleri yer almaktadır. Moment aktaran çerçeve ile çaprazların kullanıldığı modeller arasında ortaya çıkan yapı ağırlığı farkları kullanılan çelik çapraz elemanların ağırlıkları kadardır.

Tablo 3 . 5 Katlı Yapıya Ait Analiz Sonuçları

\begin{tabular}{lcccc}
\hline \multicolumn{1}{c}{ 5 Katlı Yapı } & \multirow{2}{*}{ Ăğırlık(kN) } & Periyot & \multicolumn{2}{c}{ Tepe Noktası Yerdeğiştirmesi } \\
& & Mod1(sn) & X Yönü (mm) & Y Yönü (mm) \\
\hline Moment Aktaran & 22320 & 1.17 & 15.58 & 22.36 \\
Dıșmerkez Diyagonal & 22369 & 1.02 & 13.60 & 15.81 \\
Dıșmerkez V & 22447 & 0.97 & 12.81 & 14.11 \\
Dıșmerkez Ters V & 22447 & 0.91 & 11.74 & 14.76 \\
\hline
\end{tabular}

Tüm modeller uygulandıkları çelik çaprazlar ile birlikte en ekonomik çözümü verecek şekilde tekrar tasarımı yapıldığında, yapılara ait elde edilen değerler Tablo 4'de görülmektedir.

Tablo 4. 5 Katlı Yapılarda Çapraz Elemanların Etkileri

\begin{tabular}{lcccc}
\hline $\begin{array}{c}\text { Yapının Tekrar } \\
\text { Boyutlandırılmış Hali }\end{array}$ & Ağırlık(kN) & $\begin{array}{c}\text { Periyot } \\
\text { Mod1 (sn) }\end{array}$ & \multicolumn{2}{c}{ Tepe Noktası Yerdeğiştirmesi } \\
X Yön (mm) & Y Yönü (mm) \\
\hline Moment Aktaran & 22320 & 1.17 & 15.58 & 22.36 \\
Dışmerkez Diyagonal & 21751 & 1.11 & 17.40 & 19.33 \\
Dışmerkez V & 21770 & 1.05 & 15.59 & 17.79 \\
Dışmerkez Ters V & 21770 & 1.01 & 14.89 & 15.99 \\
\hline
\end{tabular}

Tablo-4'de görüldüğü üzere; çelik çaprazların yatay yönde kazandırdığı rijitlikle de periyot değerlerinin düştüğü gözlenmektedir. Burada ki periyot değerinin en düşük olduğu çapraz türünün yine Dışmerkez Ters V çapraz olduğu gözlenmiştir. Yapının tepe noktasında ki yer değiştirme değerlerinde ise periyot değerlerinde olduğu gibi çelik çaprazların eklenmesiyle kazanılan yanal rijitlik sayesinde yerdeğiştirme değerleri azalmaktadır. Tabloda; X yönündeki yer değiștirmelerin $Y$ yönündeki yerdeğiștirmelere göre daha az olduğu gözlenmiştir. Bu durum, yapının $\mathrm{Y}$ doğrultusundaki boyutunun, $\mathrm{X}$ doğrultusundaki boyutuna göre daha az olmasında kaynaklanmaktadır. En düşük yatay yerdeğiştirme değerlerinin Dışmerkez Ters V çaprazının kullanıldığı yapıda ortaya çıktığı gözlenmektedir. Modellere uygulanan çaprazlarla birlikte tekrar tasarımı yapılmasıyla, yapı ağırlıklarının 5 katlı bir yapı için sınırlı düzeyde azaldığı gözlemlenmiştir. Tablo-4' de görüldügü üzere incelen örnek modeller arasından Dişmerkez Ters $V$ çapraz kullanılması yanal rijitliklerin artırılması konusunda en uygun tercih olabileceği görülmektedir.

\section{Sonuç ve Öneriler}

$\mathrm{Bu}$ çalışmada çelik taşıyıcı sistemden oluşan bir yapıda kullanılan dışmerkez çelik çaprazların yapı davranışı üzerine etkileri irdelenmeye çalışılmıştır. Bu doğrultuda 
tasarlanan az katlı sayılabilecek 3 ve 5 katlı modeller Moment Aktaran, Dışmerkez Diyagonal, Dıșmerkez V ve Dıșmerkez Ters V çaprazlı olarak çözümlenmiștir. Çalıșmada elde edilen sonuçlara göre çelik çaprazların moment aktaran çerçeveye göre yapıyı yanal yüklere karşı daha rijit bir hale getirdiği görülmektedir. Bu kazanılan rijitlik sayesinde çaprazların kullanıldı̆̆ı modellerin moment aktaran çerçeve modeline göre periyot değerlerinin azaldığı görülmüștür. Dıșmerkez çaprazların eklendiği yapılar içerisinde; Dıșmerkezi V çapraz ile Dıșmerkezi Ters V çaprazların, Dıșmerkezi Diyagonal çapraza göre olumlu yönde daha iyi bir katkısının olduğu görülmektedir. 3 ve 5 katlı yapıların analizleri neticesinde Dıșmerkez Ters V çapraz türünün yapıda periyot ve yer değiștirme sonuçlarına göre en fazla katkıyı yaptığı görülmektedir. Çaprazların kullanıldı̆̆ı modellerde çaprazlarında etkisi dikkate alınarak tekrar boyutlandırıldığında, yapının toplam ağırlıklarının da azaldığı gözlemlenmektedir. Özellikle yanal ötelemenin etkili olduğu çok katlı yapıların tasarımında, çaprazların kullanımı, yapısal ağırlık üzerindeki değișim oranının daha fazla olacağı beklenilmektedir. Aynı zamanda kat sayısı daha fazla olan yüksek yapılarda kullanılan eleman sayılarının da fazla olması sebebiyle, yapılarda çaprazların kullanılması sayesinde toplam yapı ağırlığını azalması konusundaki etkisinin daha belirgin olması beklenilmektedir.

Sonuçlar irdelendiğinde Dışmerkez çapraz türlerinin yapıya olan en büyük katkısının yatay yer değiştirmeleri sınırlandırması olduğu gözlemlenmiştir. Ele alınan örnek 3 ve 5 katlı yapıların analizleri sonucu elde edilen değerleri incelendiğinde her iki yapı modeli için en etkili sonuç sergileyen çapraz türünün Dışmerkezi Ters V çapraz olduğu görülmüştür.

\section{Kaynaklar}

1. Celep D. Çelik bir yapıda deprem yüklerinin çelik çaprazlar veya betonarme perdelerle taşınması, Yüksek Lisans Tezi, Fen Bilimleri Enstitüsü, İstanbul Teknik Üniversitesi Fen Bilimleri Enstitüsü, İstanbul, 2007.

2. Doğan A. Merkezi Çelik çaprazlı çerçevelerin tasarım kurallarının 2007 deprem yönetmeliğine göre incelenmesi, Yüksek Lisans Tezi, Fen Bilimleri Enstitüsü, İstanbul Teknik Üniversitesi Fen Bilimleri Enstitüsü, İstanbul, 2007.

3. Ceylan ÖG. 10 Katlı çelik bir büro binasının Eurocode 3 göre karşılaştırmalı boyutlandırılması, Yüksek Lisans Tezi, Fen Bilimleri Enstitüsü, İstanbul Teknik Üniversitesi Fen Bilimleri Enstitüsü, İstanbul, 2007.

4. Çileli E. Çok katlı çelik yapılarda çaprazlı çerçeve sistemlerin DBYBHY 2007'ye göre tasarımı ve süneklik düzeylerinin karşılaştırılması, Yüksek Lisans Tezi, Fen Bilimleri Enstitüsü, Sakarya Üniversitesi, Sakarya, 2008.

5. Ercan, A. 10 Katlı çelik bir yapının deprem yükleri altında tasarımı, Yüksek Lisans Tezi, Fen Bilimleri Enstitüsü, İstanbul Teknik Üniversitesi Fen Bilimleri Enstitüsü, İstanbul, 2008.

6. Turgut CU. Dış merkez çelik çapraz perdeli bir yapının DBYBHY 2007 kurallarına göre değerlendirilmesi, Yüksek Lisans Tezi, Fen Bilimleri Enstitüsü, İstanbul Teknik Üniversitesi Fen Bilimleri Enstitüsü, İstanbul, 2009.

7. Dizdar O. Merkezi çaprazlı çelik çerçevelerin sismik performansları. Yüksek Lisans Tezi, Fen Bilimleri Enstitüsü, Gebze Yüksek Teknoloji Enstitüsü Deprem ve Yapı Bilimleri Anabilim Dalı, Gebze, 2009.

8. Ar E. Çelik yapıların tasarım metodları ve bunların karşılaştırılması. Yüksek Lisans Tezi, Fen Bilimleri Enstitüsü, Dokuz Eylül Üniversitesi Fen Bilimleri Enstitüsü, İzmir, 2009. 
9. Özel Ö. Çok katlı çelik bir yapının tasarımında deprem ve rüzgar yüklerinin karşılaştırılması, Yüksek Lisans Tezi, Fen Bilimleri Enstitüsü, İstanbul Teknik Üniversitesi Fen Bilimleri Enstitüsü, İstanbul, 2009.

10. Kul E. Çok katlı çelik yapılarda yatay yük kapasitesini artırmada kullanılan elemanların etkinliğinin incelenmesi. Yüksek Lisans Tezi, Fen Bilimleri Enstitüsü, Karadeniz Teknik Üniversitesi, Trabzon, 2010.

11. Alıcıoğlu MB. Merkezi çelik çaprazlı yapılarda uygun çapraz kesiti geometrisinin ve çapraz türünün belirlenmesi. Yüksek Lisans Tezi, Fen Bilimleri Enstitüsü, Sakarya Üniversitesi Fen Bilimleri Enstitüsü, Sakarya, 2011.

12. Sivritepe $S$. Çok katlı betonarme yapılarda yanal rijitliği arttırmada kullanılan yöntemler. Yüksek Lisans Tezi, Fen Bilimleri Enstitüsü, Eskişehir Osmangazi Üniversitesi Fen Bilimleri Enstitüsü, Eskișehir, 2011.

13. Ülker M. AISC 360-10 ve Türk Deprem Yönetmeliği (DBYBHY, 2007)' ne göre çelik yapıların tasarımı. Yüksek Lisans Tezi, Fen Bilimleri Enstitüsü, Fırat Üniversitesi Fen Bilimleri Enstitüsü, Elazığ, 2014.

14. Akgönen A. Yüksek sünek merkezi çaprazlı çelik çerçevelerin yatay yükler altında davranışının incelenmesi. KSU Müh. Bilimleri Dergisi, 2017; 20(3): 1623.

15. Çavdar Ö. Farklı çapraz elemanlı çelik yapıların dinamik davranışının incelenmesi. 7. Çelik Yapılar Sempozyumu; 27-29 Ekim 2017; Gaziantep, Türkiye.

16. Vetr M. Experimentally and analytically study on eccentrically braced frame with vertical shear links. The Structural Design of Tall and Special Buildings, 2018.

17. Korkmaz A, Ay Z, Çelik D. Merkezi çaprazlı çelik yapıların deprem davranışlarının incelenmesi, Sigma 26(1): 58-68, İstanbul, 2008.

18. Arıbaş $S$, Sancıoğlu $S$, Çarbaş $S$. Dışmerkez V çaprazların çelik bir yapı üzerinde incelenmesi. KMÜ Mühendislik ve Doğa Bilimleri Dergisi, 2019; 1(1): 79-97.

19. Bayram B, Sancıoğlu S, Çarbaş S. Çelik bir yapıda dışmerkez diyagonal çaprazların etkisi. KMÜ Mühendislik ve Doğa Bilimleri Dergisi, 2019; 1(1): 128145.

20. Yaman Z, Ağcakoca E. Dairesel kesite sahip merkezi çelik çaprazların performans analizi. Sakarya Üniversitesi Fen Bilimleri Enstitüsü Dergisi, 2018; 22(2): 340349.

21. TBDY-2018, Türkiye Bina Deprem Yönetmeliği. Ankara, Türkiye, 2018.

22. TS EN 1991-1-4.Yapılar Üzerindeki Etkiler - Bölüm 1-4 : Genel Etkiler - Rüzgar Etkileri Ankara : TSE Teknik Kurulu, 2007.

23. TS EN 1991-1-3. Yapılar Üzerindeki Etkiler - Bölüm 1-3 : Genel Etkiler - Kar Yükleri, Ankara : TSE Teknik Kurulu, 2007.

24. Çelik Yapıların Tasarım, Hesap ve Yapımına Dair Esaslar. Ankara: Türk Standardları Enstitüsü, 2016.

25. SAP2000, Linear and Nonlinear Static and Dynamic Analysis of ThreeDimensional Structures, Advanced Version 19, Computer and Structures. 